\title{
INFLUENCE OF TEST QUANTITY ON LOOSE SAND SHEARING STRENGTH PARAMETERS
}

\author{
Šarūnas Skuodis ${ }^{1}$, Arnoldas Norkus ${ }^{2}$ \\ ${ }^{1,2}$ Department of Geotechnical Engineering, Faculty of Civil Engineering, Vilnius Gediminas Technical University, \\ Sauletekio al. 11, LT-10223 Vilnius, Lithuania
}

E-mail: 'Sarunas.Skuodis@vgtu.lt (corresponding author); ${ }^{2}$ Arnoldas.Norkus@vgtu.lt

\begin{abstract}
Investigation of the shear strength properties of Klaipeda sand by simple shear test is presented. The characteristic values of the angle of internal friction $\varphi_{k}$ and the cohesion $c_{k}$ are obtained via the least squares method and various factors of influence are elucidated. The investigation reveals the test quantity to have a significant influence on the characteristic shear strength parameters for loose sand. The processed characteristic magnitude of the angle of internal friction varies within $16.14^{\circ}$ ( 3 tests) and $27.02^{\circ}$ (36 tests) bounds, that of the characteristic cohesion varies within $74.18 \mathrm{kPa}$ (3 tests) and $1.12 \mathrm{kPa}$ (36 tests) bounds. The above mentioned shear strength properties confirm the linear Mohr-Coulomb strength criterion obtained via processing the test data. The same scatter of characteristic shear strength parameters variation is obtained when the peak shear stress are recorded for horizontal displacement magnitude of $5 \mathrm{~mm}$. In this case the obtained characteristic angle of the internal friction varies within the bounds of $17.38^{0}$ ( 3 tests) and $26.79^{0}$ (36 tests), and that of characteristic cohesion within various within $-68.82 \mathrm{kPa}$ ( 3 tests) and $1.18 \mathrm{kPa}$ (36 tests) bounds. The authors recommend performing at least 18 experimental tests in order to avoid high influence on statistical coefficient of confidence level $t_{\alpha}$ and on the number of degrees of freedom $k$.
\end{abstract}

Keywords: simple shear test, method of least squares, angle of internal friction, cohesion, loose sand, constant vertical stress.

\section{Introduction}

The characteristic values of soil shear strength properties (Mohr-Coulomb strength criterion is generally acknowledged as a general strength criterion) are employed in geotechnical codified design (see CSN EN 1997-1:2004). The angle of internal friction $\varphi$ and the cohesion $c$ are the strength parameters, prescribing the above mentioned linear strength criterion.

The direct shear test is widely applied for determining the parameters in laboratory conditions of the above mentioned shear strength criterion due its simplicity and time resources.

Statistical methods may be used when selecting characteristic values of geotechnical parameters, but they are not mandatory (Frank et al. 2004). The characteristic values of the above mentioned strength parameters confirm the fixed quantils of fixed reliability of parameters is prescribed as codified requirement (Amšiejus et al. 2006). When statistical methods are used, the code recommends that the calculated probability of a worse value governing the occurrence of the limit state considered should not be greater than 5\% (Frank et al. 2004). The design values of strength parameters are subsequently obtained by combining characteristic values of the parameters with the partial safety coefficients depending on the design approach and certain additional factors (e.g. model) introduced in annexes to national regulations.

The characteristic values of soil shear strength parameters generally are calculated by processing the test results applying the least squares method (Amšiejus et al. 2006). As each test is associated with certain expenses, i.e. direct cost and indirect cost (larger number of tests decreases the actual value conforming to the prescribed reliability level), the question of "rational or sufficient" number of tests should be considered. According to
Bond \& Haris (2008), it is not necessary to perform a big number of soil shear tests, the quantity of 2-4 tests is sufficient. Such small quantity of tests looks attractive for consumer or/and designer, because it is possible to get soil shear strength results during a short period (about few days) and at seemingly small expenses for geotechnical investigations. It just depends on the selected test method (realized via certain device) to be employed: the simple shear test (Thay et al. 2013), the direct shear test (Bathurst et al. 2008; Kalhor 2012; Zydron, Zawisa 2011) or the triaxial test (Dirgèlienè et al. 2013). The above listed techniques require different time resources, knowledge and skills to perform the test.

All these devices prescribe the systematic and nonsystematic inaccuracies (due to their principle and constructional schemes) also depending on physical soil states, varying among the loose and dense ones. When the peak soil shear strength values (Roopnarine et al. 2012) are determined for the same investigated soil, it is possible to get different values of the angle of internal friction $\varphi$ and the cohesion $c$ (Nguyen, 2009; Skuodis et al. 2013; Bareither et al. 2008; Ghazavi et al. 2008). Determining of residual soil shear strength values (Chin, Sew 2001) is not analysed in the current investigation.

Considering sandy soils, Thermann et al. (2006) indicated three influencing factors for magnitudes of internal friction $\varphi$ and cohesion $c$, namely: the influence of different laboratory assistant, the influence of displacement rate (Huy et al. 2006) and the influence of specimen size. Generalization of the above-mentioned factors, actually being different by nature, disregards another governing factor, i. e. test quantity, significantly conditioning the accuracy of soil strength parameters to be determined.

The aim of the current investigation is to identify the influence (sensitivity) of the required quantity of tests for determining the characteristic soil shear strength 
parameters $\varphi_{k}$ and $c_{k}$. and to propose the "rational" quantity of tests to ensure the sufficient accuracy of strength parameters.

\section{Test data processing}

The peak strength is determined according to the maximum ratio of shear and normal stresses, i.e. according $\tau / \sigma=\max$. The angle of the internal friction $\varphi$ and the cohesion $c$ are calculated applying the least squares method technique.

When proceeding the method, it is necessary to calculate mean values for angle of internal friction and cohesion (Olsson et al. 2007; Amšiejus et al. 2010; Užpolevičius 2006), namely:

$$
\begin{aligned}
& \operatorname{tg} \varphi_{\text {mean }}=\left(n \sum_{i=1}^{n} \tau_{f, i} \sigma_{i}-\sum_{i=1}^{n} \tau_{f, i} \sum_{i=1}^{n} \sigma_{i}\right) /\left(n \sum_{i=1}^{n} \sigma_{i}^{2}-\left(\sum_{i=1}^{n} \sigma_{i}\right)^{2}\right) \\
& c_{\text {mean }}=\left(\sum_{i=1}^{n} \tau_{f, i} \sigma_{i}^{2}-\sum_{i=1}^{n} \sigma_{i} \sum_{i=1}^{n} \tau_{f, i} \sigma_{i}\right) /\left(n \sum_{i=1}^{n} \sigma_{i}^{2}-\left(\sum_{i=1}^{n} \sigma_{i}\right)^{2}\right)
\end{aligned}
$$

where: $n$ is the quantity of tests; $\tau_{f, i}$ is the peak value of shearing stress, $\mathrm{kPa} ; \sigma_{i}$ is normal stress at shear plane, $\mathrm{kPa}$.

The characteristic values of the angle of internal friction and the cohesion are obtained by:

$$
\begin{aligned}
& \operatorname{tg} \varphi_{k}=\operatorname{tg} \varphi_{\text {mean }} / \gamma_{\text {tg } \varphi} ; \\
& c_{k}=c_{\text {mean }} / \gamma_{c} \text {, }
\end{aligned}
$$

where: $\gamma_{\operatorname{tg} \varphi}$ and $\gamma_{c}$ are the soil reliability coefficients for the angle of internal friction and the cohesion, respectively.

The reliability coefficients in formulae (3) and (4) are calculated by (Amšiejus et al. 2006):

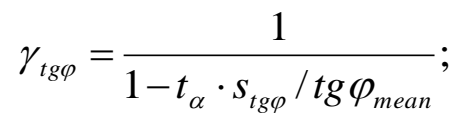

$$
\begin{aligned}
& \gamma_{c}=\frac{1}{1-t_{\alpha} \cdot s_{c} / c_{\text {mean }}},
\end{aligned}
$$

where: $s_{\operatorname{tg} \varphi}$ and $s_{c}$ are the mean square deviations of the estimates for the angle of internal friction and the cohesion respectively; $t_{\alpha}$ is a statistical coefficient (Amšiejus et al. 2006) corresponding to the confidence level $(\alpha=0.95)$ and the number of degree of freedom calculated by $k=n-2$ (here $n$ is the number of soil shear tests or cuts of a specimen).

The values $s_{\operatorname{tg} \varphi}$ and $s_{c}$ in formulae (5) and (6) are obtained by (Amšiejus et al. 2006):

$$
\begin{aligned}
& s_{t g \varphi}=\sqrt{n \cdot S /\left(n \sum_{i=1}^{n} \sigma_{i}^{2}-\left(\sum_{i=1}^{n} \sigma_{i}\right)^{2}\right)(n-2)} ; \\
& s_{c}=\sqrt{\sum_{i=1}^{n} \sigma_{i}^{2} \cdot S /\left(n \sum_{i=1}^{n} \sigma_{i}^{2}-\left(\sum_{i=1}^{n} \sigma_{i}\right)^{2}\right)(n-2)},
\end{aligned}
$$

where: $S$ is the squares of the deviations of distances from each soil cut point. $S$ is determined by:
$S=\sum_{i=1}^{n}\left(\left(\sigma_{i} \cdot \operatorname{tg} \varphi_{\text {mean }}+c_{\text {mean }}\right)-\tau_{f, i}\right)^{2}$

The soil shear strength confidence limits applying the least squares method is determined by:

$\tau_{\text {mean }}-t_{\alpha} \cdot \sqrt{s_{\tau\left(\sigma_{i}\right)}^{2}}<\tau_{\left(\sigma_{i}\right)}<\tau_{\text {mean }}+t_{\alpha} \cdot \sqrt{s_{\tau\left(\sigma_{i}\right)}^{2}}$.

where: $s_{\tau(\sigma i)}$ is an estimation of the soil shear strength variance; $\tau_{\text {mean }}=\sigma_{i} \operatorname{tg} \varphi_{\text {mean }}+c_{\text {mean }}$.

The soil shear strength variance estimation is calculated considering the relation (covariance moment) between the angle of internal friction and cohesion:

$$
s_{\tau\left(\sigma_{i}\right)}^{2}=s_{c}^{2}+s_{t g \varphi}^{2} \cdot \sigma_{i}^{2}+2 \cdot \sigma_{i} \cdot \operatorname{cov}(\operatorname{tg} \varphi, c),
$$

where: $\operatorname{cov}(\operatorname{tg} \varphi, c)$ is the covariance moment between the angle of internal friction and the cohesion.

The covariance moment is calculated by:

$$
\operatorname{cov}(\operatorname{tg} \varphi, c)=\sum_{i=1}^{n} \sigma_{i} \cdot S /\left(\left(n \sum_{i=1}^{n} \sigma_{i}^{2}-\left(\sum_{i=1}^{n} \sigma_{i}\right)^{2}\right)(n-2)\right) \text {. }
$$

\section{Experimental set-up}

The Klaipeda sand (can be considered as characteristic Baltic Sea-shore sand) is under the investigation. The mineralogical composition of sand is described basically by dominating ingredients, namely: $85 \%$ silica and $6 \%$ sunstone with remaining contribution of carbonate, mica and some other minerals (Amšiejus et al. 2010).

This type of sand was selected due to the naturally higher smoothness and roundness of the sand grains (Dundulis, Gadeikis 2006; Medzvieckas et al. 2008). The same soil sample for soil shear tests was used for testing in order to ensure the same conditions of test procedures. A soil grading curve (Fig. 1) has not changed during all tests since a relatively small vertical stress was employed for shear tests (results are presented in Skuodis and Kavrus, 2012).

The air-dry Klaipeda sand sample was prepared from disrupted soil structure conforming an initial soil void ratio $e_{o}=0.784$. Determined solid density of sand sample is $\rho_{s}=2.650 \mathrm{~g} / \mathrm{cm}^{3}$. The principle constructional scheme of the employed universal shear device ADS 1/3 (Wille Geotec Group 2010) is presented in Fig. 2.

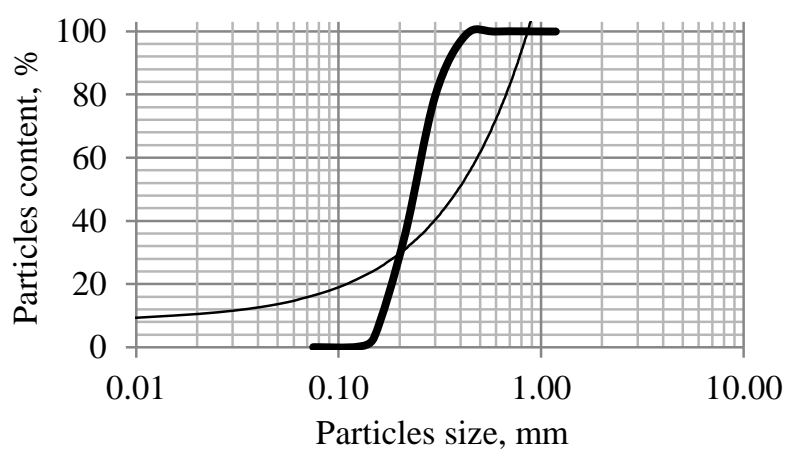

Fig. 1. Baltic Sea-shore sand grains distribution curve. 


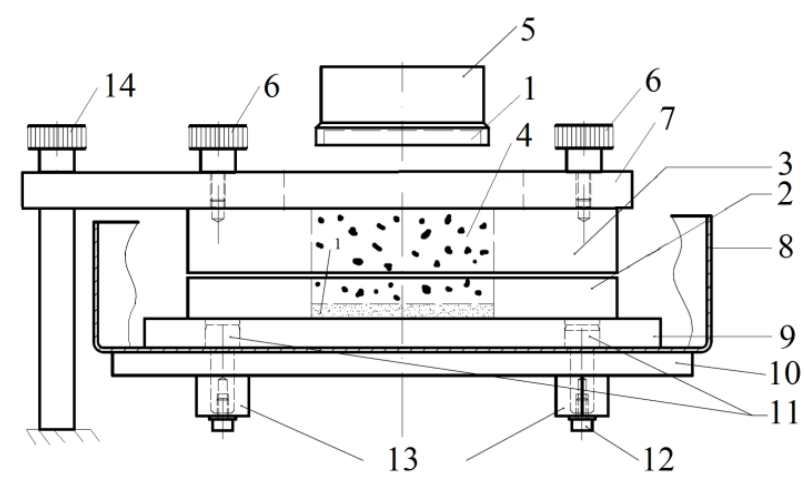

Fig. 2. Constructional scheme of simple shear device. 1 - porous stone; 2 - lower shearing ring; upper shearing ring; 4 - soil sample; 5 - load piston; 6 - gap position screws; 7 - rigid plate; 8 - water bath; 9 - lower shearing ring orientation plate; 10 - flexible base plate; 11 - orientation screws; 12 - flexible base plate fixing to the rails; 13 - rails; 14 - upper ring rigid support.

Before shearing the soil sample was compressed (preloaded) by a constant vertical stress ramp of $50 \mathrm{kPa} / \mathrm{min}$ until the fixed vertical load levels $(100 ; 200$; $300 \mathrm{kPa}$ ) were reached. 36 tests were done in total, which correspond to 3 different above-mentioned vertical load magnitudes. The soil was sheared (cut) under the constant horizontal displacement with $0.5 \mathrm{~mm} / \mathrm{min}$ velocity until the horizontal displacement at shear plane reached the limit of $9 \mathrm{~mm}$ (usually employed to fix the cut of specimen) and constant vertical loading magnitudes of 100,200 and $300 \mathrm{kPa}$, respectively. The tests were performed when the initial height of the gap between the upper and the lower shearing rings was $1 \mathrm{~mm}$ and they were fixed during the test.

\section{Analysis of the obtained results}

The characteristic shear strength graph of the investigated sand (Fig. 3) for loose soils was processed by maintaining the constant vertical load on the top of the sample.

The determined soil peak shear stress values for 36 tests are given in Fig. 4. The peak shearing stress values have been obtained for maximum ratio of shear and normal stresses, i.e. according $\tau / \sigma=\max$. The coefficient of determination is $R^{2}=0.9448$ for the processed tests. It is more than 0.8 , meaning high matching the linear relationship between the normal and shear values at shear plane of cut specimens (Rukšènaite 2011; Rice 2010). According to Fig. 4, the calculated characteristic angle of the internal friction is equal to $\varphi_{k}=27.02,{ }^{0}$ and the cohesion $c_{k}=1.12, \mathrm{kPa}$.

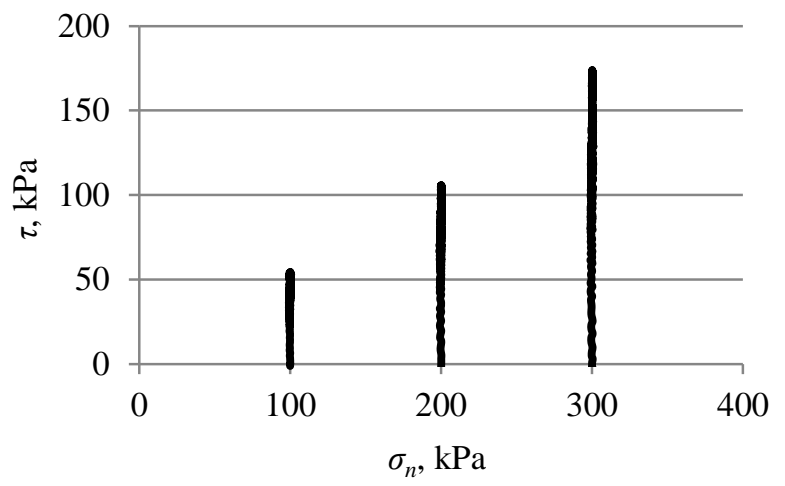

Fig. 3. Loose sand shearing stress path.

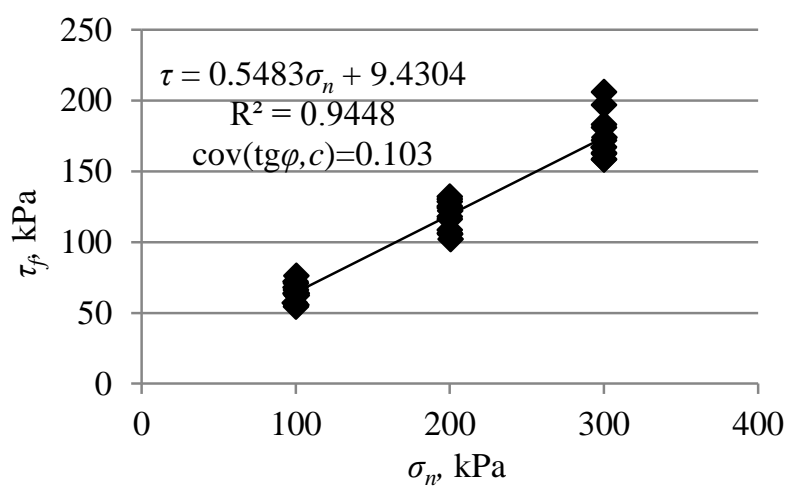

Fig. 4. Peak values of loose sand shear strength parameters.

Fig. 5 illustrates the relation of shearing stress peak values versus the horizontal displacement. An analysis of Fig. 5 obviously shows that the maximum shear stress is reached when horizontal displacement is equal to $u=5 \mathrm{~mm}$ for loose sand under investigation.

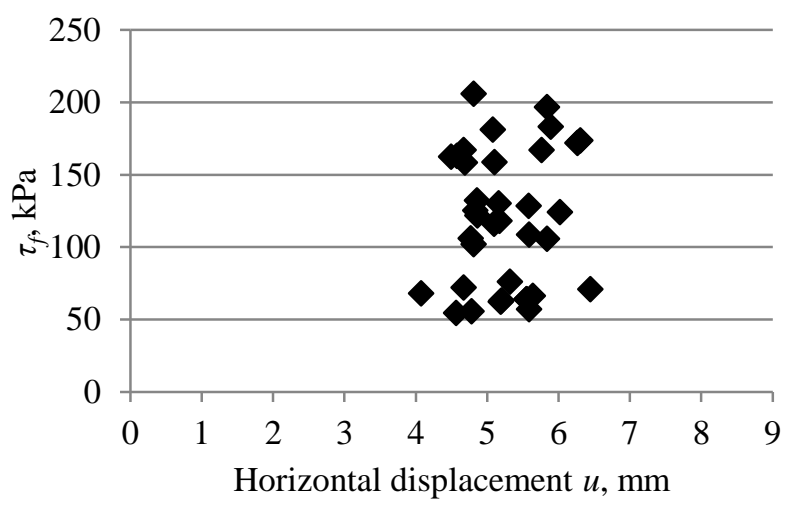

Fig. 5. Peak shearing stress versus horizontal displacement.

For the accurate revealing of the influence of the test quantity on the characteristic shear strength parameters, the relationships between test quantity and the angle of internal friction $\varphi_{k}$ (Fig. 6) and that of cohesion $c_{k}$ (Fig. 7) have been developed. 


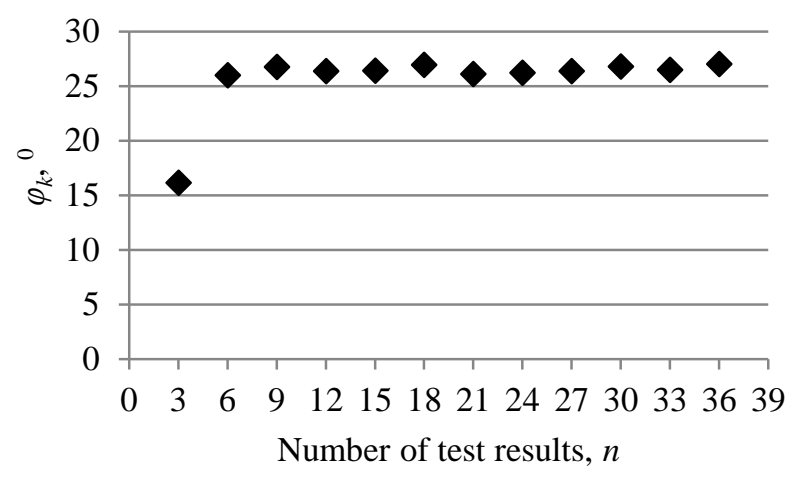

Fig. 6. Characteristic angle of internal friction versus test quantity.

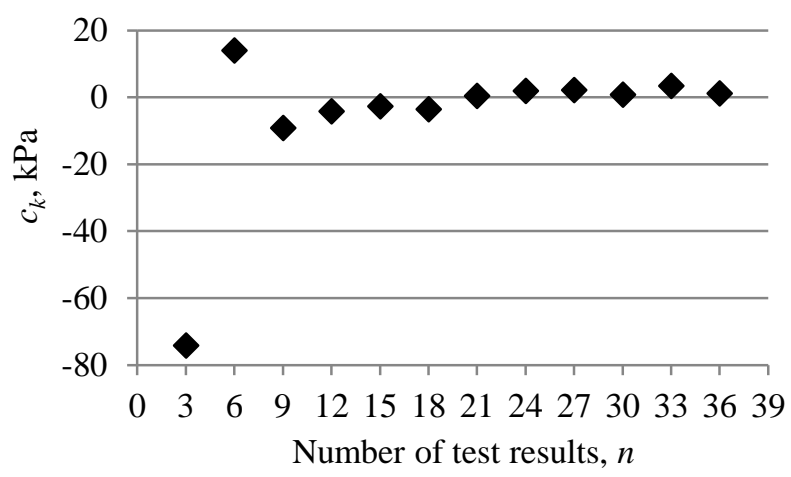

Fig. 7. Characteristic cohesion versus test quantity.

The analysis of results presented in Figs. 6-7 clearly shows that the number of 3 shear tests is actually insufficient to conform to the least squares method calculation requirements, i.e. statistical analysis requirements in a proper way. We remind the reader that the confidence level of $\alpha=0.95$ for characteristic values is applied. For 3 tests the statistical coefficient depending on the confidence level and the number of degree of freedom is equal to $t_{\alpha}=6.3$; that of for 36 tests $t_{\alpha}=1.69$. Due to this reason the characteristic angle of internal friction is equal to $\varphi_{k}=16.14,{ }^{0}$ and cohesion is equal to $c_{k}=-74.18, \mathrm{kPa}$.

Note that naturally the sandy soil or sand cohesion is approximately equal to zero (Amšiejus et al. 2006). Larger values or especially negative values of cohesion mean only the formal line strength criterion (linear function of $c_{k}$ and $\varphi_{k}$ ) intercept the ordinate axis, being the result of processing the test results using the least square method techniques. Therefore, the "direct" employment of cohesion results, both positive and negative, needs to be revised and applied in proper magnitudes for actual geotechnical design purposes.

Coefficient $t_{\alpha}$ actually has no influence on the soil shear strength parameters, when the quantity of tests reaches the number of 18 .

The characteristic shearing stress values always should be lower the one corresponding to the confidence lower limit and never can appear between them an intersection. The example explanation in case of 3 tests results graphically is explained in Fig. 8.

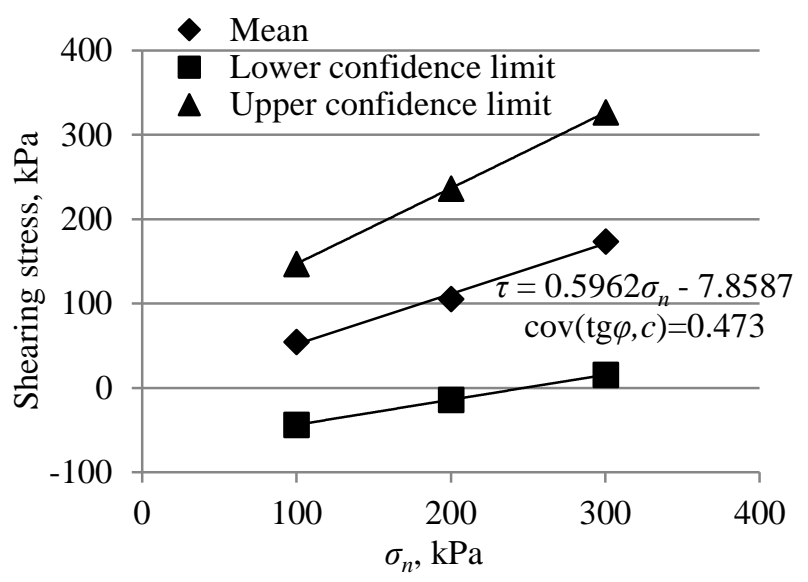

Fig. 8. Confidence limits of characteristic soil shear strength parameters (3 test results).

Fig. 8 clearly shows that only for 3 test results the confidence limits increase and that of for 36 tests results the confidence limits decrease (Fig. 9).

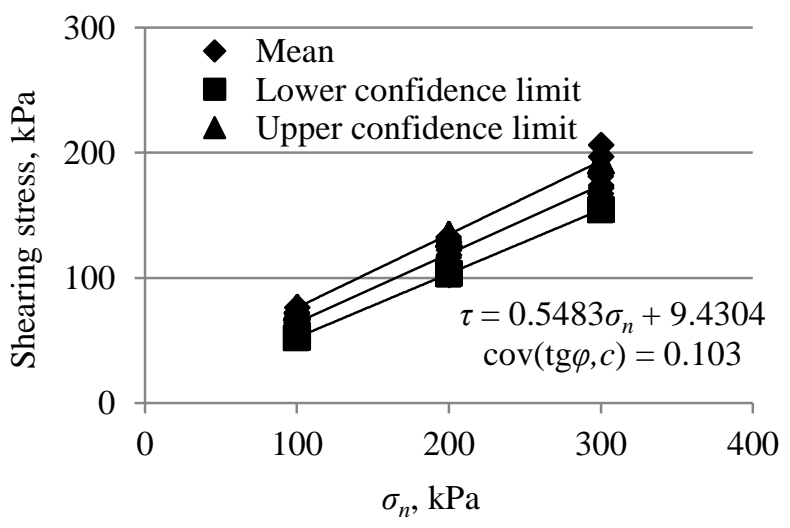

Fig. 9. Confidence limits of characteristic soil shear strength parameters (36 test results).

When analysing the results given in Fig. 9, one can find that some mean values are out of the upper confidence limit for vertical stress of $300 \mathrm{kPa}$. This is due to $t_{\alpha}$ conforming confidence level $\alpha=0.95$. To avoid this phenomena it is necessary to perform calculations for $\alpha=0.99$.

The random variables processing using the Microsoft Excel Sampling command (McCullough, Heiser 2008) were compiled for identifying the real test quantity influence on the characteristic shear strength parameters. The increments of the characteristic angle of internal friction (see Fig. 10) and the cohesion (see Fig. 11) versus of test quantity were analysed.

Figs. 10-11 show the same character of test quantity influence on soil characteristic shear strength parameters as in Figs. 6-7, i.e. the quantity of 18 tests yields positive cohesion $c_{k}$. 


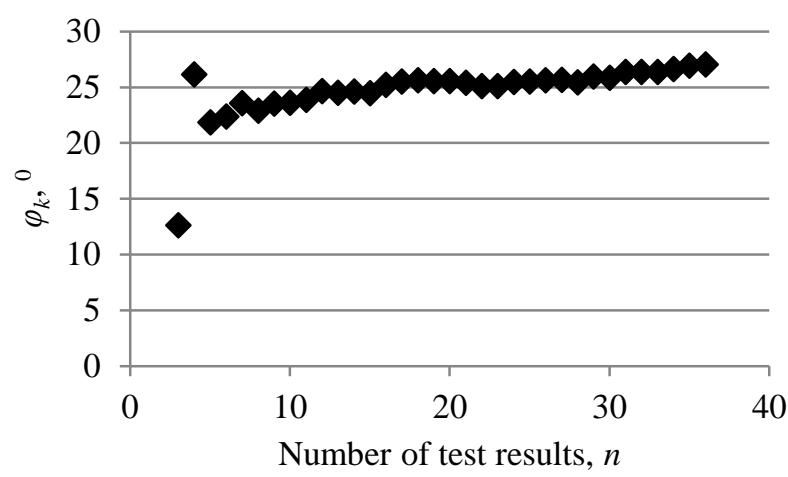

Fig. 10. Characteristic angle of internal friction versus test quantity increment.

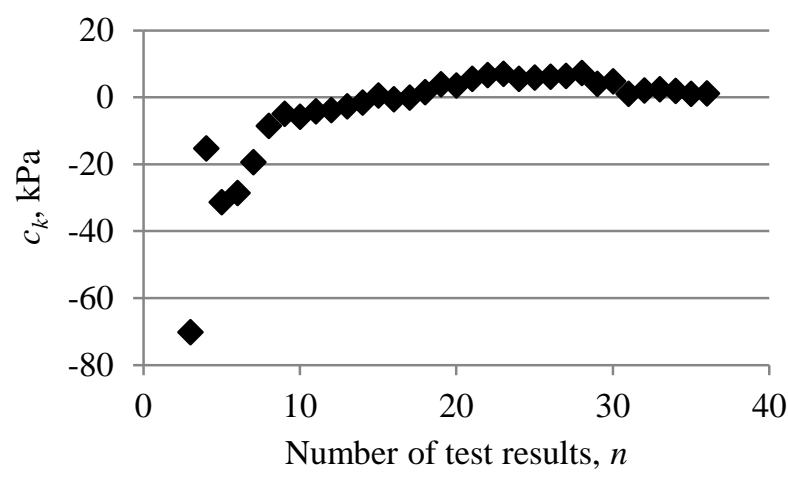

Fig. 11. Characteristic cohesion versus test quantity increment.

Our investigation proved that peak shearing values for tested Baltic Sea-shore sand is detected when the horizontal displacement reaches the value of $\sim 5 \mathrm{~mm}$. Hence, the characteristic soil shear strength values have been calculated fixing the sample shear (cut) conforming to the horizontal displacement magnitude of $5 \mathrm{~mm}$ (see Fig. 12).

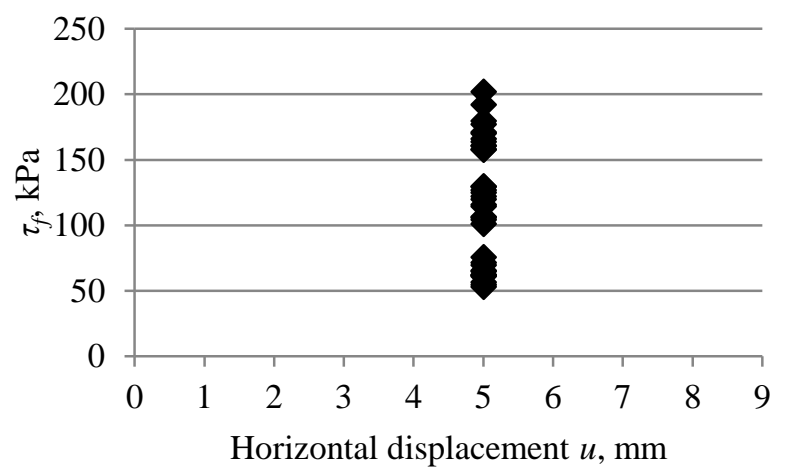

Fig. 12. Peak shearing stress versus horizontal displacement $(\mathrm{u}=5 \mathrm{~mm})$.

The shear strength values for the horizontal displacement of $5 \mathrm{~mm}$ versus the number of tests are as shown in Figs. 13 and 14 for the angle of internal friction and the cohesion, respectively.

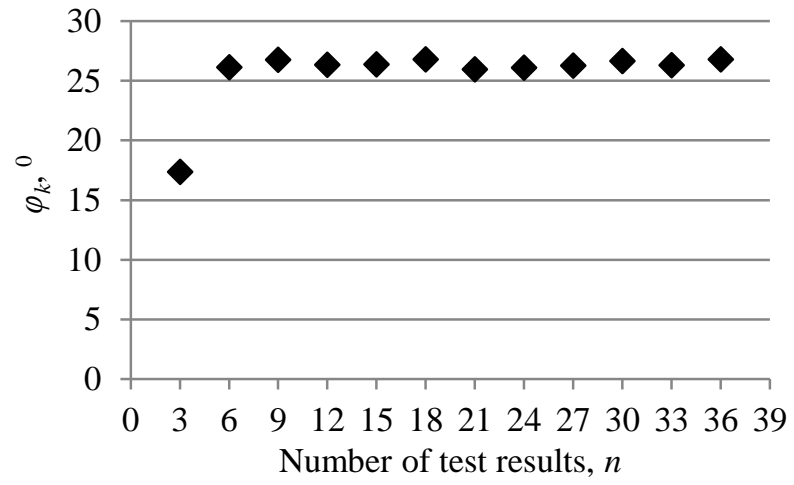

Fig. 13. Characteristic angle of internal friction versus test quantity $(\mathrm{u}=5 \mathrm{~mm})$.

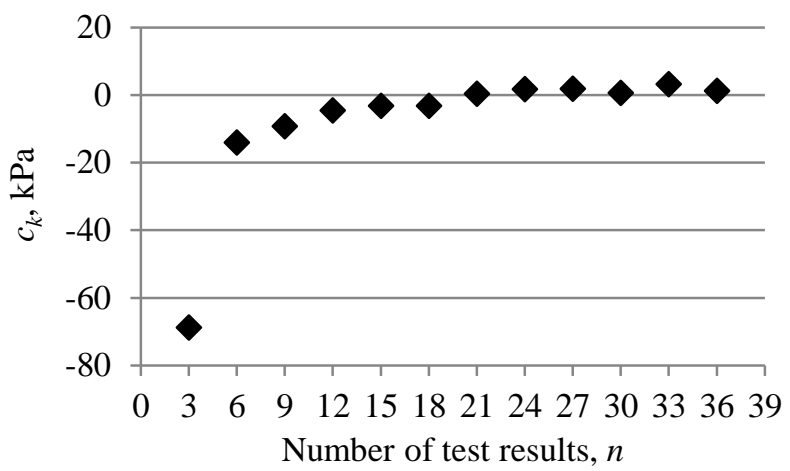

Fig. 14. Characteristic cohesion versus test quantity $(u=5 \mathrm{~mm})$.

The analysis of Figs. 13-14 shows the same tendency as described above, namely: for small quantity of tests the characteristic value of cohesion is negative and for larger quantity of tests (more than 18) cohesion changes to a positive value. For calculation of the characteristic angle of internal friction it is enough to perform at least 9 tests and the value will be almost the same if calculations are done by processing 36 test results.

\section{Conclusions}

The investigation revealed that the test quantity for loose sand has a significant influence on the characteristic shear strength parameters. The calculated characteristic magnitude for the angle of internal friction varies within the bounds of $16.14^{\circ}$ (3 tests) and $27.02^{\circ}$ (36 tests), that of for the cohesion within the bounds of $-74.18 \mathrm{kPa}$ (3 tests) and $1.12 \mathrm{kPa}$ (36 tests), respectively. This scatter of characteristic shear strength parameters is explained by the procedures of the least squares method calculation techniques.

The same character of characteristic shear strength parameters variance was obtained when the peak shearing stress was taken for horizontal displacement magnitude equal to $5 \mathrm{~mm}$. In this case the calculated characteristic angle of internal friction varies within the bounds of $17.38^{\circ}$ (3 tests) and $26.79^{\circ}$ (36 tests), and that for characteristic cohesion magnitude within the bounds of $68.82 \mathrm{kPa}$ (3 tests) and $1.18 \mathrm{kPa}$ (36 tests).

General finding of the current investigation is that the analysis of test quantity influence on characteristic soil shear strength parameters demonstrated the necessity to 
perform more than 3 tests. The authors recommend to perform at least 18 tests in order to avoid high influence of coefficient of confidence level $t_{\alpha}(\alpha=0.95)$ in concert with the degree of freedom $k=n-2$ ( $n$ is quantity of shear tests).

\section{Acknowledgement}

The equipment and infrastructure of Civil Engineering Scientific Research Center of Vilnius Gediminas Technical University was employed for investigations.

\section{References}

Amšiejus, J.; Mackevičius, R.; Medzvieckas, J.; Sližytė, D.; Stragys, V. V., 2006. Gruntu fizines ir mechanines savybès: Laboratoriniai darbai [Soil physical and mechanical properties, Laboratory testing]. Vilnius: Tecnika. 164 p. (in Lithuanian). http://dx.doi.org/10.3846/855-S

Amšiejus, J.; Dirgèlienè, N.; Norkus, A., 2010. Analysis of methods for evaluation of soil shear strength parameters. International Conference on Modern building materialas, structures and techniques (MBMST), pp.1077-1082.

Amšiejus, J.; Kačianauskas, R.; Norkus, A.; Tumonis, L., 2010. Investigation of sand porosity via odometric testing. The Baltic Journal of Road and Bridge Engineering, 5(3), pp. 139-147. http://dx.doi.org/10.3846/bjrbe.2010.20

Bareither, C. A.; Edil, T. B.; Benson, C. H.; Mickelson, D. M., 2008. Geological and Physical Factors Affecting the friction angle of Compacted Soils. Journal of Geotechnical and Environmental Engineering, 134(10), pp. 1476-1489. http://dx.doi.org/10.1061/(ASCE)10900241(2008)134:10(1476)

Bathurst, R. J.; Althoff, S.; Linnenbaum, P., 2008. Influence of Test Method on Direct Shear Behaviour of Segmental Retaining Wall Units. Geotechnical Testing Journal, 31(2), pp. 1-9.

Bond, A.; Harris, A., 2008. Decoding Eurocode 7, Taylor \& Francis. 621p.

Chin, T. Y.; Sew, G. S., 2001.The determination of shear strength in residual soils for slope stability analysis. Seminar Cerun Kabangsaan, Cameron Highlands, 14-15 May, pp. 1-18.

CSN EN 1997-1:2004. Eurocode 7: Geotechnical design - Part 1: General rules, $168 \mathrm{p}$.

Dirgèlienè, N.; Norkus, A.; Amšiejus, J.; Skuodis, Š.; Žilionienè, D. Stress-strain analysis of sand subjected to triaxial loading. The Baltic Journal of Road and Bridge Engineering, 8(1), pp. 25-31.

Dundulis, K.; Gadeiskis, S., 2006. Influence of morphometric characteristics of sand particles on the strength parameters of sand soils in Lithuania. Geologija, 53, pp. 52-56.

Frank, R.; Bauduin, C.; Driscoll, R.; Kavvadas, M.; Krebs Ovesen, N.; Orr, T.; Schuppener, B., 2004. Designer's guide to EN 1997-1. Eurocode 7: Geotechnical design - general rules. Thomas Telford Publishing, Thomas Telford Ltd, 1 Heron Quay, London. 216 p.

Ghazavi, M.; Hosseini, M.; Mollanouri, M. A., Comparison between Angle of Repose and Friction Angle of Sand. In: The $12^{\text {th }}$ International Conference for International
Association for Computer Methods and Advances in Geomechanics (IACMAG), in 1-6 October, 2008, Goa, India.

Huy, N. Q.; Tol, A. F.; Hölscher, P., 2006. Report: Laboratory investigation of the loading rate effects in sand. Delft University of Technology, Delft, the Netherlands, $46 \mathrm{p}$.

Kalhor, A., 2012. The shear strength analyses of soil with various compactions under vertical load in direct shear test. International Research Journal of Applied and Basic Sciences, 3, pp. 2815-2821.

McCullough, B. D.; Heiser, D. A., 2008. On the accuracy of statistical procedures in Microsoft Excel 2007. Computational Statistics \& Data Analysis, 52(10), pp. 4570-4578. http://dx.doi.org/10.1016/j.csda.2008.03.004

Medzvieckas, J.; Gadeikis, S.; Dundulis, K., 2008. Properties of fine soils of Klaipeda port area. Geologija, 50(3), pp. 206-211.

http://dx.doi.org/10.2478/v10056-008-0046-x

Nguyen, G., 2009. The analysis of factors influencing the values of soil shear strength parameters obtained by direct shear test. Studia Geotechnica et Mechanica, 31(1), pp. 51-72.

Olsson, U.; Engstrand, U.; Rupšys, P., 2007. Statistiniai metodai. Mokomoji knyga [Statistical methods. Course book], Akademija, 138p. (in Lithuanian).

Rice, J. A., 2010. Mathematical Statistics and Data Analysis. Third Edition. Thomson Brooks/Cole. 34 p.

Roopnarine, R.; Eudoixe, G.; Gay, D., 2012. Soil Physical Properties as Predictors of Soil Strength Indices: Trinidad Case Study. Geomaterials, 2012(2), pp. 1-9.

Rukšenaitè, J., 2011. Impact of Factor Rotation Methods on Simulation Composite Indicators. Mathematical Modelling and Analysis, 16(3), pp. 418-431.

http://dx.doi.org/10.3846/13926292.2011.602436

Skuodis, Š.; Norkus, A.; Dirgèlienè, N.; Šlečkuvienè, A., 2013. Sand shearing peculiarities using direct shear device. Proceedia Engineering, 11th International Conference on Modern building materialas, structures and techniques (MBMST), Amsterdam: Elsevier Science Ltd. 57, pp. 1052-1059.

Skuodis, Š.; Kavrus, A., 2012. Atskirų grunto dalelių formos kitimas prieš ir po spūdumo bandymo [Particle shape evaluation before and after compression]. Science - Future of Lithuania: Civil and Transport Engineering, Aviation Technologies, Vilnius: Technika, 4(4), pp. 340-345. (in Lithuanian).

Thay, S.; Likitlersuang, S.; Pipatpongsa, T. Monotonic and Cyclic Behaviour of Chiang Mai Sand Under Simple Shear Mode. Geotecnical and Geological Engineering, 31, pp. 67-82.

Thermann, K.; Gau, C.; Tiedemann, J., 2006. Shear strength parameters from direct shear tests - influencing factors and their significance. IAEG2006 Paper number 484, pp. 1-12.

Užpolevičius, B., 2006. Statinių tyrinejjimas, bandymas ir vertinimas [Building research, testing and evaluation]. Vilnius: Technika. 136 p. (in Lithuanian). http://dx.doi.org/10.3846/834-S

Wille Geotec Group., 2010. Universal direct shear test device ADS 1/3. Göttingen, Germany.

Zydron, T.; Zawisa, E., 2011. Shear strength investigation of soils in landslide areas. Geologija, 53(3), pp. 147-155. http://dx.doi.org/10.6001/geologija.v53i3.1895 